Perspectiva Geográfica

ISSN 0123-3769 (Impreso) - 2500-8684 (En línea)

Vol. 21 No. 1 de 2016

Enero - Junio

pp. 11-32

\title{
La conformación del espacio social a través del gusto por lo pintoresco ${ }^{1}$
}

\author{
Social Space Conformation for the Sake of the Picturesque
}

Augusto Solórzano

Para citar este artículo utilice el nombre completo así:

Solórzano, A. (2016). La conformación del espacio social a través del gusto por lo pintoresco. Perspectiva Geográfica, 21(1), 11-32.

\section{Resumen}

En la propedéutica del gusto, que Joseph Addison elaboró en torno a la naturaleza, lo curioso, lo sorprendente, lo interesante y lo agradable, es posible identificar una conciencia espacializante que desde lo sensorial restauró los mecanismos éticos y estéticos que gobernaron la vida social del siglo XVIII. Mediada por el placer y la imaginación, esta conciencia posibilitó el surgimiento de un espacio para el encuentro, que operó gracias a la simpatía, el diálogo y la discusión sobre los aspectos banales de la vida cotidiana. Conforme lo plantea Addison, la subjetividad y las emociones son pilares para la construcción de la vida pública. En conclusión, se argumenta el valor que la imaginación, los recuerdos, los desplazamientos por los jardines, las prácticas sensoriales y el goce por los placeres sencillos que ofrece el entorno tienen como antecedentes filosóficos de una geografía de las emociones.

Palabras clave: geografía de la subjetividad, paisaje-jardín, pintoresco, propedéutica del gusto.

1 Este texto hace parte del proyecto "Poéticas de lo artificial", que está inscrito en el Sistema de Información de la Investigación de la Universidad Nacional de Colombia, Facultad de Arquitectura, Escuela de Artes, Sede Medellín.

2 Doctor en Filosofía, Universidad Pontificia Bolivariana. Profesor asistente, Universidad Nacional de Colombia, sede Medellín, Facultad de Arquitectura. portalsolorzano @gmail.com 


\begin{abstract}
In the propaedeutic of preferences which Joseph Addison constructed upon the concepts of the picturesque, curiosity, surprise, the interesting and the pleasant, it is possible to identify a specific spatial consciousness. This consciousness, which emerges from the senses, restored the ethic and aesthetic mechanisms which characterized social living in the eighteenth century. Based within the imagination and its pleasures, this very consciousness created a space which allowed and nurtured a discussion based in turn on mutual sympathetic aspects of daily life. As result, and fitting with Addison, subjectivity together with the emotions are the pillars upon which everyday life is built. In conclusion, the article argues for the existence of an emotional geography. This geography has its philosophical antecedents anchored in the imagination which encompasses everything from memories and the sensual experience of walking through a landscape and the banality of finding pleasure in simple objects.
\end{abstract}

Keywords: subjectivity geography, landscape-garden, picturesque, propaedeutic of taste. 
1. Indicaciones previas: Joseph Addison como precursor de lo pintoresco

Las nuevas perspectivas que surgen en las distintas ciencias sociales y humanas exigen establecer un diálogo entre el pasado y el presente que ensanche el horizonte epistemológico y que permita ver el hoy como una realidad indivisible. Este es el caso de la teoría estética propuesta por algunos filósofos del siglo XVIII, cuyas ideas permiten identificar puntos capitales que la geografía de las emociones discute hoy.

No está por demás señalar que la actualidad filosófica de las emociones, del agrado y lo curioso depende de las motivaciones e interés del intérprete que sea capaz de efectuar una praxis fundiendo el horizonte del pasado con el objeto de interpretación, en eso que Gadamer concibe como el principio de la historia efectual. De estas circunstancias nace el hecho de que prácticas específicas sobre las que la geografía de la emociones posa su lupa, tales como caminar, las experiencias sensoriales enlazadas con los recuerdos o la imaginación, así como el diseño del entorno, hayan sido descritas y teorizadas por pensadores que rompieron con los prejuicios impuestos por la estética clásica y cuyos planteamientos aproximaron una mentalidad de cambio al introducir la sensibilidad como al aglutinante de los aspectos sociales, políticos y económicos.

Uno de esos filósofos es Joseph Addison (1672-1719), autor y divulgador de unas ideas que fundamentan el marco referencial e histórico de lo pintoresco. Como eslabón intermedio entre una teoría clasicista y una moderna, la invitación de Addison para faltar a las antiguas reglas clásicas (The Spectador, n. ${ }^{\circ}$ 29) revoluciona una burguesía en formación que iniciaba el cultivo de una serie de gustos y de una incipiente teoría del arte; sus paradigmáticos planteamientos, difundidos en la revista The Spectador, acerca de recorrer la naturaleza con la brújula de lo sensual y lo fantasioso, permiten descubrir el valor que el entorno tiene a la hora de producir efectos sensoriales en el espacio íntimo, público y privado de los individuos.

En lo que corresponde a la psicología sensualista que estructura la concepción estética de Addison, puede decirse que el sentimiento de lo sublime, la experiencia de lo inhabitual y la sensación de lo 
agradable son circunscritos a los placeres de la imaginación. Unos y otros se enriquecen gracias a la capacidad asociativa que caracteriza a la fantasía, permitiendo crear y experimentar cosas nuevas, cuya combinación abre un infinito abanico para el goce. A saber, el análisis comparativo entre los jardines franceses e ingleses constituye un documento que, desde la filosofía, la poesía y la literatura, estudia la subjetividad plegada en el paisaje geográfico, el valor que el entorno tiene para el fortalecimiento de los lazos afectivos y el rol que juega el desplazamiento a la hora de establecer las relaciones visuales y emocionales con el lugar.

Entre líneas, es posible leer el valor que Addison otorga a las experiencias cotidianas y a la noción de mundo vivido y construido colectivamente como esa amalgama de intercambios éticos y estéticos que se dan en el espacio a partir de las percepciones afectivas que hacen que lo ordinario sea valorado como extraordinario. Estas ideas son apenas el inicio de una teoría filosófica y literaria que influyó de manera definitiva en toda Europa, y constituyen el motor de arranque de un giro copernicano en lo que a la teoría estética se refiere. Detrás de abrir el abanico de los placeres y de ampliar el rango de los goces se encuentra una transformación radical de la vida cotidiana que le hace entender a la clase burguesa que el disfrute ha de buscarse en las cosas sencillas del día tras día y que postergarlo para la eternidad carece de sentido; para hacerlo posible fue necesario crear y reconocer ambientes, espacios y paisajes en los que estuviera presente la singularidad y el detalle curioso que cautiva la atención. Tras bambalinas hay una transformación radical de la cultura material que impacta la vida económica, política y cultural de Europa. La expansión de un turismo y un entretenimiento cuyos hoteles comienzan a pensarse como ambientes que favorezcan la conversación informal e ingeniosa (Pochat, 2008) es apenas un ejemplo que deja entrever la importancia que el espacio del ocio tiene en la sociedad burguesa, así como la relevancia de un naciente consumo experiencial, del intercambio cultural y del turismo concebido como industria que se alimenta de la curiosidad. Esto es un abrebocas de las implicaciones que tuvo el entorno construido a la hora de anclar la experiencia banal y sensible como el motor que enriquece los goces en la vida cotidiana. 
A través de las descripciones de Addison sobre los paisajes naturales y los ambientes construidos es posible entender cómo la emocionalidad aglutina al hombre con un lugar; de igual forma, cómo se proyecta y experimentan emociones particulares en los objetos de la naturaleza, por sencillos o sublimes que sean, $\mathrm{y}$, sobre todo, cómo se determina que la valoración del espacio depende de las vivencias, emociones y sensaciones que un sujeto experimenta en el lugar. No sobra mencionar que todo esto gana sentido en la medida en que pueda ser compartido, disfrutado y discutido con los demás.

\section{El anclaje de lo pintoresco}

Con este telón de fondo puede ratificarse que lo pintoresco emerge en la modernidad del siglo XVIII a través de una serie de actividades culturales relacionadas directamente con la valoración sensible del espacio de la naturaleza, con el gusto por lo agradable y con la curiosidad, la novedad, el turismo y lo interesante. De igual suerte, están las reflexiones filosóficas que ahondan en el cultivo de los placeres en la vida cotidiana, y que asocian el espacio de la naturaleza con una burguesía emergente re- cién insertada en el seno de lo urbano. El orden en el que germina lo pintoresco está determinado por una clara afectación de la comunicabilidad de quienes comienzan a habitar la ciudad moderna: individuos tan diversos y extraños que, a causa del desplazamiento, enfrentan serias dificultades para encontrar los principios que les permita una apertura al sentimiento de los otros.

Lo dicho hasta aquí supone que este calificativo estético se relieva en un momento histórico en el que surgen una serie de preguntas sobre cómo espacio y sociedad pactan en la modernidad nuevas rutas de interacción sobre la base de una resignificación de la naturaleza cuyo fundamento es, justamente, el gusto por lo agradable. Someramente, vale recordar que el siglo XVIII, catalogado por Dickie (2003) como el Siglo del gusto, es un periodo efervescente en lo que se refiere a la teoría estética; la razón radica, principalmente, en que se pone en tela de juicio la idea de que el mundo en común pueda ser reducido a esquemas conceptuales, argumentos demostrativos o conceptos determinados. Al igual que Addison (1712, ed. 1991), autores como Shaftesbury (1711, 
ed. 1964), Hutcheson (1725, ed. 1992), Burke (1757, ed. 1987), Kant (1798, ed. 1935; 1790; ed. 1991) o Hume (1741, ed. 1989; 1757, ed. 1990), entre otros, apelaran a los diversos matices del gusto para demostrar que los juicios valorativos son comunicables y dan lugar a la pluralidad de puntos de vista y, por consiguiente, a una discusión sedimentada en la opinión (Meinen) y la creencia (Glauben) que no alcanza a resolverse de manera definitiva, demostrando que en cuestión de gustos no hay un consenso universal y restricto.

Otro punto capital para recrear la emergencia de lo pintoresco es la búsqueda que emprenden los filósofos por establecer y diferenciar unas categorías estéticas que permitan describir, deducir, acotar y clasificar los diversos modos en que se presentan los fenómenos estéticos; fenómenos que, por demás, hoy están presentes en la geografía de las emociones; entre ellos pueden mencionarse los desplazamientos por los lugares, la construcción de la vida pública a partir de las emociones o los efectos que la imaginación tiene en la construcción del espacio urbano.
Justamente, fruto de esa especificación sistemática de los predicados estéticos es que emerge, de la mano de Addison (1712, ed. 1991), la diferencia entre la belleza, la grandeza y lo singular, tres grandes categorías que el romanticismo resinificará como lo bello, lo sublime y lo pintoresco. Este debate, que se mantiene a lo largo del siglo XVIII, permite identificar en cada autor diferentes matices sobre las dimensiones que el hecho estético tiene para la ética, la moral, la ideología, la política y la antropología, matices que son inabarcables en este escrito, pero que, sin lugar a dudas, pueden ser leídos con la lupa de la geografía emocional, a fin de elicitar nuevas interpretaciones plegadas en las reflexiones estéticas y filosóficas.

Detrás de todo esto está la intersubjetividad, que juega un papel prioritario, en tanto se convierte en el aglutinante que le da sentido al entorno natural, al paisaje, pero también a una serie de actividades banales con las que, desde una ética-estética, es posible construir, reconocer y departir con los demás los espacios de vida. Ejemplos relevantes son los recorridos que se hacían en compañía por el campo, los paseos a las fincas de recreo los 
fines de semana, la valoración estética de la jardinería, la pintura de curiosidades, el placer que suscitan los suvenires o las descripciones de costumbres en libros de viaje. $\mathrm{Al}$ discernir un rasgo en común a todas estas actividades, aparece en la escena el gusto por lo agradable; este describe detalladamente las valoraciones sensibles que emergen al desplazarse por un lugar, la importancia que para la imaginación tienen los encuentros sensoriales, así como la preponderancia que ofrecen los lugares para la activación sensorial. Notorio es para la experiencia, el enriquecimiento imaginativo que brindan los ambientes construidos (jardines) y la naturaleza intocada y tosca, el deleite por lo desconocido, los recuerdos y la percepción cambiante. No sobra aclarar que este gusto se basa en un sentimiento privado y relativo a referencias propias, que no reclama el acuerdo de todos, pero que gana sentido en la medida en que sea comunicable y compartido intersubjetivamente, promoviendo, antes que todo, la discusión y el intercambio de creencias y opiniones. Conviene subrayar también que todas estas actividades ponen en juego, a través de la revelación, una reciprocidad entre el mundo material externo y el mundo inter- no del sujeto. Aquí, lo pintoresco y el juicio por lo agradable convierten en esencial todo aquello que se acostumbra a presentar como inesencial y superfluo, transformando lo prosaico en algo nuevo, inédito y misterioso. En otras palabras, transforman lo extraordinario en lo ordinario y hacen que el cuerpo individual, el cuerpo social y el cuerpo cósmico se sintonicen en el reconocimiento y el valor que los pequeños goces, las sorpresas y las curiosidades ofrecen para la vida. Falta por decir que, en todo esto, la autonomía del gusto, como afecto, potencia el reconocimiento de la novedad.

En estas prácticas, actividades y acciones, el diálogo juega un papel prioritario, pues supone que la convivencia, el estar con los otros, es una experiencia que no se puede idealizar, sino que parte de la espontaneidad y del disfrute de la compañía de los demás. De hecho, convertir la naturaleza y sus curiosidades en un motivo de diálogo y de aprehensión subjetiva del mundo en común, en el que prima lo sensorial y lo agradable, reivindica que el comportamiento práctico y moral del estar con los otros no es susceptible de prescripciones y preconceptos establecidos por una 
autoridad, sino que es un proceso que se experimenta como un ensanchamiento de nuestra propia individualidad (Ruiz, 2012, p. 210). Así las cosas, es claro que la percepción paisajística de la naturaleza fue un factor clave que les permitió, primero, a la aristocracia, y, luego, a la burguesía representarse a sí mismas y, sobre todo, representar sus roles en la sociedad. Con vehemencia se dice que es en este momento que el territorio se convierte en mercancía y que detrás de esto opera una ideología que enmascaró la asimetría social y el ostracismo que las nuevas clases sociales enfrentaban en el espacio urbano luego de abandonar la vida rural. $\mathrm{Si}$ bien es indiscutible la verdad contenida en este enfoque crítico del paisaje, también lo es el hecho de que, a la par, surge una espacialidad que deviene de la experiencia contemplativa y que involucra la creación de un dispositivo ético estético en el cual lo agradable se refleja en nuevas prácticas, hábitos, ritos y costumbres que orientaron los asuntos de la vida compartida; esto es, los modos de relacionarse entre los individuos modernos. Tras emerger como una conciencia ética-estética que a través del lenguaje potencializa un acuerdo libre e indeterminado, lo pintores- co toma como propio el espacio del paisaje y sus ambientes, las prácticas de desplazamiento que involucran la experiencia sensorial y las experiencias paisajísticas que detonan efectos para la imaginación. En otras palabras, reconfigura los contenidos y el sentido de la vida social a través del juicio de gusto por lo agradable, potencializando eso que Merleau-Ponty denomina intercorporalidad y cuya definición depende enteramente del diálogo. En la experiencia del diálogo, se constituye entre el otro y yo un terreno común; mi pensamiento y el suyo no forman más que un solo tejido; mis frases y las del interlocutor vienen suscitadas por el estado de la discusión, se insertan en una operación común de la que ninguno de nosotros es creador. Se da ahí un ser a dos, y el otro no es para mí un simple comportamiento en el campo trascendental, ni tampoco yo en el suyo; somos, el uno para el otro, colaboradores en una reciprocidad perfecta; nuestras perspectivas se deslizan una dentro de la otra; coexistimos a través de un mismo mundo (Merleau-Ponty, 1945, ed. 1996, p. 366).

Articulado a ello, la estructura ambiental de lo agradable del paisaje y de sus prácticas brinda al individuo 
un sinnúmero de estímulos que, al no agotar del todo su significado, encuentran un terreno abonado para desplegarse en el mundo de la charla que piensa M. Heidegger; ese mundo donde lo cotidiano se hace palabra, donde el cotorreo se superpone a la comunicación cargada de contenidos, donde la broma gana a lo trascendental, donde el Sensus communis supera al sujeto trascendental, la imaginación trasciende la ley y el gusto sobrepasa el deber. Por supuesto, se trata de ese mundo en el que el palabreo le permite al sujeto tomar consciencia de la forma como el espacio doméstico y la vida cotidiana se relacionan con el lugar y el momento donde discurre, posibilitándole también observar cómo afronta quehaceres cotidianos como pensar, desplazarse o conversar.

Es así como el cuerpo se reviste de sensaciones que dan vida a un mundo; a esto, la fenomenología clásica francesa, abanderada por Merleau-Ponty (1945, ed. 1996, p. 25), llamará dialéctica vivida; la sociología cultural de Certeau, espacio practicado (1980, ed.1990, pp. 172-175), y la hermenéutica de la facticidad heideggeriana, Co-mundo (1999, p. 9) o mundo en común. Estos conceptos dan lugar a un ensanchamiento espacial de ese mundo compartido que apela a la naturaleza, la novedad, la curiosidad y al lenguaje para aludir expresamente al enriquecimiento de las relaciones con los otros, pero que también es espacio, en la medida en que forja y amplía la experiencia de la percepción y los sentidos al revestirlos de mayor expresividad, significados y valores. Bajo esta premisa, es posible reconocer lo pintoresco como un dispositivo polisensorial que, de un lado, acompaña de manera indisociable la codificación de las significaciones que lo agradable tiene para la vida social, y, por otro, le apuesta al conocimiento del espacio de la naturaleza a través de los sentidos, al tiempo que promociona el sentimiento de placer como base para alcanzar a través del gusto acuerdos libres, espontáneos e indeterminados. Así, lo curioso, lo banal, lo interesante y lo atractivo para la imaginación, presente en el paisaje y en las experiencias paisajísticas, amplía el repertorio de temas para que se lleve a cabo una coexistencia compartida, un espacio participativo, pero, también, una antropología del cuerpo vivido en la que prima el placer por las cosas más prosaicas, como caminar por un jardín, contemplar una ruina, 
pasear desprevenidamente por el campo, emocionarse con un suvenir o sorprenderse con una costumbre curiosa que resulta ajena. Interesa destacar aquí esa valoración estética y emocional que surge en el desplazamiento y que ensancha el repertorio de nuestros goces, una práctica que transforma simbólicamente el territorio, un instrumento estético para el deleite, y una forma autónoma de arte.

Hoy vemos claramente cómo pensadores de una estética expandida, los cuales reconocen la importancia del andar como práctica estética que propicia impresiones sensibles de calidad excepcional, se focalizan en los detalles del desplazamiento, tras considerar que la travesía es una actitud que se convierte en forma y una manera crítica de construir el espacio.

El andar (marche) designa un límite en movimiento que, en realidad, no es más que lo que solemos llamar frontera; esta va siempre a la par con las franjas, los espacios intermedios, los contornos indefinibles, que solo podemos ver realmente cuando andamos por ellos: "Un propósito como este conlleva un auténtico posicionamiento 'político' -en el sentido primordial de la palabra-, un modo de considerar el arte, el urbanismo y el proyecto social a una distancia igual y suficiente entre ellos, con el fin de dilucidar con eficiencia estos vacíos de los que tanta necesidad tenemos para vivir bien" (Careri, 2009, p. 16).

Se comprende así que esa noción de desplazamiento, apuntalada en el siglo XVIII y reclamada hoy, abrió la puerta a la configuración de un nuevo sentido del espacio en el que lo prosaico (entendido aquí como ese contorno indefinible) termina por poner en tela de juicio nuestra proximidad con el mundo, propiciando que lo se percibía como exterioridad se perciba ahora como una revelación en la que lo más cercano a nosotros se renueva en su facticidad. Una radiografía de este asunto puede hallarse en el primer capítulo de la tesis doctoral de Lévinas, titulada Totalidad e infinito. Ensayo sobre la exterioridad, en donde se lee:

Lo Otro metafísicamente deseado no es "otro" como el pan que como o como el país en el que habito, como el paisaje que contemplo, o como yo a veces yo mismo a mí mismo, este "yo", este "otro". De estas realidades 
puedo "nutrirme" y, en gran medida, satisfacerme, como si me hubiesen siempre faltado. Por ello mismo, su alteridad se reabsorbe en mi identidad de pensante o de poseedor (Lévinas, 1961, ed. 1987, p. 57).

Pese a la belleza iluminadora de estas palabras cargadas de metafísica, hay que decir que la comprensión real del significado de eso "Otro" que llama Lévinas (y que, para el caso, es el paisaje, sus ruinas, sus formas estriadas y sus curiosidades), va más allá de simplemente satisfacer una necesidad o una carencia. De hecho, ello supondría que lo Otro ha sido ocupado por un saber teórico experimental que define o, por lo menos, presupone y da por sentado los principios de la sensibilidad, la corporalidad y la espacialidad. Por el contrario, se trata de establecer a través de eso Otro un espacio para que la experiencia particular y colectiva se revista de valores y significaciones sorprendentes que alimenten el espacio expresivo del hombre y fortalezca su vida en común.

\section{La acuñación de un concepto y la propedéutica comprensiva de la naturaleza}

Líneas atrás se mencionaba cómo lo pintoresco se convierte en el siglo XVIII en un dispositivo de la polisensorialidad que supone el juicio sobre lo agradable. La idea de asumir que las curiosidades del paisaje superan lo visible y que eso agradable deviene de estímulos a todos los sentidos por igual está contenida en los primeros filósofos que le apostaron a la teorización de lo pintoresco como categoría estética. Sobre este punto en particular, en el que el canto de un pájaro, el correr de un arroyo, el departir el fin de semana en una finca de recreo o el contemplar una ruina se traduce en experiencia corporal y en una ampliación de los goces corporales, Addison pone su lupa teórica y consolida, a través de sus 555 números seguidos fielmente por más de 6.000 suscriptores, una propedéutica del gusto y de la valoración ética y estética alrededor, justamente, de lo singular y curioso. De igual forma, sienta, en los inicios del siglo XVIII, las bases de lo que actualmente se considera la construcción geográfica edificada sobre las interacciones sensibles que el hombre mantiene con el espacio. 
En su lucha contra las rígidas reglas del clasicismo racionalista, Addison había empezado a publicar en 1712 una serie de artículos en el periódico The Spectador, los cuales conformarían luego su famosa obra Los placeres de la imaginación y otros ensayos (1712, ed. 1991); allí la imaginación es la fuente principal de la actividad creadora y el detonante para que los sentidos capten la emoción del paisaje en una suerte de geografía afectiva que reconcilia lo corporal con lo sensitivo. He aquí un fragmento del número 37, en el que las experiencias sensoriales, enlazadas con recuerdos de la percepción, describen la experiencia significativa del lugar (se transcriben las mayúsculas originales):

Sir Roger me ha entretenido una Hora con una Descripción de su Finca, la cual está situada en una especie de Selva, como a unas cien millas de Londres, y parece un pequeño Palacio Encantado. A sus Rocas se le han dado la forma de Grutas Artificiales cubiertas con Madreselvas y Jazmines. Los Bosques están talados formando Caminos con sombra, entrelazados como Parra, y llenos de Cajas con Tortugas. Las Fuentes están hechas para correr entre Guijas, $\mathrm{y}$ de ese modo aprendieron a Murmurar muy agradablemente. Asimismo están conectadas a un Hermoso Lago habitado por una Pareja de Cisnes, el cual se vacía por un pequeño Arroyo que corre a través de un Médano Verde, y es conocido en la Familia por el Nombre de El Arroyo Susurrante. El Caballero de la misma manera me dice que esta Dama preserva su Juego mejor que ninguno de los Hombres de Campo, no es (dice Sir Roger) que ella ponga un Valor tan grande sobre sus Perdices y Campesinos, como sobre sus Alondras y Ruiseñores. Puesto que ella dice que cada Pájaro que se mate en su Tierra estropeará a un Consorte, y que ella indudablemente lo extrañará el Año entrante (Addison, 37, Jueves 12 de abril de 1711).

Impactar la imaginación con la riqueza del lugar, le permite a Addison divulgar, a una sociedad afectada por el ostracismo, una serie de referencias sobre cómo acceder al paisaje como medio sensorial. Al tiempo, formula el interrogante a la sociedad burguesa de cómo convertir el ambiente natural en el eje de la significación particular y co- 
lectiva. Tras determinar tres fuentes básicas por las cuales los objetos nos resultan atractivos (la belleza, la grandeza y la singularidad), se focaliza en la novedad como la verdadera causa de aquello que produce nuestra admiración. Entre las líneas de su propuesta hay una notable preocupación por vincular el cuerpo sensible con el espacio geográfico, con el paisaje, con el entorno, haciendo uso de la curiosidad que causa en nosotros una sorpresa agradable y que impulsa el motor de nuestras emociones en la vida cotidiana. Claro es que para que ello suceda es necesario que la imaginación mezcle libremente las ideas con las experiencias que producen los sentidos; de esta forma se hace posible que cada objeto sea combinado espontáneamente con otro de naturaleza similar y que, además, pueda incorporársele historias de cualquier otro tipo o asociaciones mentales que el sujeto considere pertinentes.

Lo dicho hasta aquí supone que la imaginación se convierte en la facultad de la que emana la libertad para que el sujeto asocie en su mente imágenes de distinta procedencia, rigiéndose única y exclusivamente por lo que su subjetividad le dicta libremente. A esto se añade que la imaginación aparezca como un espacio del libre albedrío donde el individuo mezcla las imágenes de su memoria con las imágenes fantásticas.

La percepción del objeto es más rica y poderosa cuando las asociaciones sensitivas se asocian con otras mentales. Así pues, cuando interactúan el sonido de una cascada y el canto continuo de las aves con una fragancia determinada, se realzan los placeres de la imaginación, y todo el paisaje que el observador contempla se torna más agradable, ya que la interacción de los distintos sentidos le permite captar con más viveza los colores dispersos por el paisaje (Solórzano, 2008, p. 31).

En esto se evidencia el valor que la plurisensorialidad tiene para el reconocimiento de la experiencia paisajística y la antropología del cuerpo vivido, aun cuando Addison sobreponga la vista sobre los demás sentidos, al reconocer que esta es más pura por no entrar en contacto directo con los objetos. La imaginación se concibe como un espacio en el que hábilmente el sujeto combina las imágenes y las asocia en total libertad para producir otras tantas mucho más ricas y 
poderosas. De ahí que su propedéutica, difundida en The Spectador, abogara para que las personas encontraran lugares donde esa imaginación se activara con más fuerza; esto conduce a reafirmar la relación plurisensorial entre el ser humano y el paisaje, pues lo pintoresco opera entre uno y otro como esa sutura que legitima la sencillez estética de la vida y vuelve a posibilitar un reencantamiento con el medio a través del dominio de los sentidos. Lo mismo habría que decir respecto al gusto por lo agradable, el cual supone que, a la hora de desplazarse, el estado subjetivo del individuo se inclina por aquellos objetos que le ofrecen una satisfacción inmediata y no tanto un concepto determinado por la razón. Así, Addison deja entrever sistemáticamente la forma como el placer se conquista a través de la imaginación, y determina el valor que para ella tiene la ficción. Al respecto, Vilard (2000, pp. 16-17) señala que una vez la ficción se incorpora al contexto de la historia individual empieza a iluminar la cotidianidad del sujeto y a configurar nuevas formas colectivas del gusto que, para ser entendidas, requieren del despliegue permanente de novedosas prácticas comunicativas, del mundo de la charla, en su sentido positivo. La ficción se reconoce como el medio que colorea las interpretaciones cognitivas para hacer que el paisaje se transforme en expresión estética y geográfica a través de un proceso acumulativo de percepciones sensoriales e imaginativas. Así, el sujeto moderno se constituye libre de ataduras normativas que le indiquen cómo disfrutar de la naturaleza y de sus curiosidades, pues el goce de la naturaleza depende de las actitudes y estados emocionales que el cuerpo adopte. El espacio en el que dicho cuerpo se apoya es el espacio de su propia experiencia impregnada por la ficción. Se trata de un cambio en la constelación de la estética y del mundo vital, que hace que el individuo pierda sus referencias seguras y, en razón de ello, empiece a desear, indagar, experimentar y conocer libremente los fenómenos y las cosas de acuerdo con elecciones particulares (Solórzano, 2008, p. 33). Caminar, comparecer frente a lo nuevo y lo extraño, es tomar conciencia del asombro agradable que se pliega en los detalles del entorno, pues, de hecho, lo agradable se reconoce como ese deleite que satisface inmediatamente un fin subjetivo. 
Al llegar aquí es necesario recordar que Addison invierte la jerarquía estética planteada tiempo atrás por Locke: considerado así el asunto, la experiencia estética devenida de la solidez, el volumen y la forma cede su lugar para privilegiar el color, el olor o el sonido, pues se asumen como ideas del ánimo y no meras cualidades materiales. De esta forma, la riqueza subjetiva de la geografía nace de un efecto imaginativo, de una afectación de los sentidos y de una asociación y deleite de ideas que son coligadas a los detalles de la realidad; para que esto suceda es necesario que la imaginación se desplace y entre en contacto directo con los aspectos singulares de los objetos. Este contexto permite inferir la manera como lo minúsculo del paisaje gana importancia dentro de su teoría; mientras la grandeza (más tarde convertida por los románticos en la categoría de lo sublime) se asume como la anchura de una perspectiva entera considerada como una sola pieza - tal como sucede con la vista amplia de un campo, un desierto, el mar, los relieves naturales-, lo singular se pliega en las minucias y aparentes insignificancias, como la irregularidad de un árbol, la textura rugosa de una ruina, la irregularidad del paisaje, lo tosco de una cabaña o las sombras y gradaciones del follaje que sorprenden el ojo.

Inventar otros mundos que pueden estar contenidos en el mundo real es el detonante para que emerja lo nuevo, lo singular. Como puede inferirse, lo nuevo es causa de sorpresas agradables y atrae la curiosidad por todos aquellos objetos, imágenes, sonidos, colores, formas y texturas del paisaje. El medio y sus cosas se cargan de extrañeza, aliviando el tedio que producen las tareas diarias. Cuando Addison le propone al espectador encontrar paisajes cargados de estímulos, esos en los que prima el correr de un arroyo alegrado con el canto de los pájaros, termina promocionando dos nuevas categorías estéticas estrechamente ligadas, cuyo trasfondo es el entretenimiento: la variedad y el movimiento. Ambas abogan para que el sujeto no se detenga permanentemente en un objeto y para que el cambio de sensaciones aumente el disfrute. Después de todo, la imaginación imprime vivacidad a las ideas y se funda con las impresiones. Gracias a su posibilidad de establecer semejanzas artificiales, la imaginación inaugura permanentemente diferentes alternativas de vida, ya que hace que seamos 
cautivados y conmovidos emocionalmente por los juicios subjetivos y por las actitudes contemplativas que sirven como telón de fondo para que nuestro juicio sea comunicable y discutible, estableciendo así vínculos de reciprocidad.

\section{Hacia una construcción ética estética del espacio social}

Vistas así las cosas, lo pintoresco se convierte en ese dispositivo ético estético que le posibilita al individuo hacer de su territorio cotidiano un laboratorio para el gozo humano; en él, la emocionalidad y los afectos conjugan la diversidad material del entorno con la diversidad sensible. De ahí se desprende que el vínculo entre el pensamiento geográfico y lo pintoresco permita convertir el paisaje como medio y fin, como necesidad y contingencia, como exterioridad e interioridad. De un lado, indiscutiblemente, esto significa una revalorización de la experiencia subjetiva capaz de integrar los componentes emotivos e imaginativos al entorno; de otro, implica la construcción de un dispositivo práctico y teórico en el que el afecto, la emoción, la pasión, la atmósfera y tantos otros componentes propios de la experiencia sensible energizan con su cariz connotativa las fuerzas de lo social, haciendo que las emociones sean protagonistas de la comprensión de la vida social. En este sentido, puede situarse a Adisson como un antecedente de los llamados giro afectivo y giro emocional que hoy orientan los nuevos tópicos del discurso estético y artístico, así como también de una geografía cultural que piensa el lugar que ocupan las emociones en la configuración de la sociedad y del espacio (Anderson y Smith, 2001).

Desde luego, la vida social sedimentada en las emociones es ese medio camino entre hacer algo y ser algo, que recientemente piensa Kartz (2001), queriendo decir con ello que la experiencia emocional capturada en forma de palabras, movimiento, descripciones e imágenes deja de ser furtiva una vez es mediada por el lenguaje. Se relieva así la importancia que la comunicabilidad por ruta de lo sensible tiene en la estructuración de los procesos sociales, pero también el papel que lo afectivo conserva en el establecimiento de nuestras relaciones con los demás y con nosotros mismos, relaciones que, por demás, abren el debate sobre dos temas trascendentales para la geografía cultural: la identidad y la pertenencia. 
Falta por decir que la construcción del espacio por ruta de la experiencia emocional o afectiva hace que, de un lado, las emociones operen como la urdimbre del tejido conectivo que vincula al hombre con el paisaje geográfico, y de otro, sean la trama para construir el paisaje emocional intersubjetivamente. Por eso, no resulta equivocado asegurar que lo pintoresco entra en el siglo XVIII a restaurar, través del gusto por lo agradable, las insuficiencias y potencialidades de la vida en común. En esto se pliega un asomo de respuesta a los interrogantes sobre qué realmente es la comunidad, planteados por Reymond (1970):

Qué cosa ha sido, qué cosa podría ser; cómo se vincula la comunidad con los individuos y las relaciones; cómo es que los hombres y mujeres, al ser comprometidos directamente, ven en ellos o más allá de ellos, pero con la mayor frecuencia, contra ellos la forma de sociedad ( $p$. 12).

Lejos de pensar en que la comunidad depende de una prefiguración o prescripción establecida u ordenada por una autoridad, se debe asumir que sus bases dependen de la posibilidad de que los individuos participen, correspondan y confluyan en el intercambio de sentimientos, ideas, juicios y opiniones desinteresadas que, por encima de cualquier utilidad individual, ponen de relieve la importancia que tienen los vínculos intersubjetivos. En ello prevalece un tránsito de un yo a un nosotros a través del sentido estético que había sido previsto por el Conde de Shaftesbury en 1711 y que se condensa en su famosa teoría del Sensus comunis. Quiere esto decir que es posible entrar en una comunión estética con el mundo, una vez que las sensaciones omniabarcadoras unen a los hombres y establecen una comunidad. El eco de esta propuesta se refleja en Davidson y Milligan (2004), al afirmar que "las emociones tienen que ser entonces consideradas como una forma de tejido conectivo que vincula las geografías experienciales de la psique y la física humana con (y dentro de) las más amplias geografías sociales del lugar" (p. 524).

En el marco de comprensión de las múltiples posibilidades para abordar la vida social desde la subjetividad, aparece Hume; en sus ideas subyace una conciencia espacial y geográfica en la que es posible 
constituir estética y, recíprocamente, al Otro, a través de la imaginación. Colorear, matizar y adornar la realidad, esto es, según sus propias palabras, "hacer soportable lo insoportable", es posible gracias a la emancipación de la imaginación, que se constituye en una fuerza que activa la comunicación y favorece los distintos puntos de vista que se exponen permanentemente dentro de la conversación, actividad que permite a la gente formar criterios generales e inalterables de aprobación o desaprobación.

De lo anterior se desprende que la complejidad del ejercicio conversacional implique crear un espacio en el que los interlocutores se desplazan de una idea a otra, de una opinión a otra, de un juicio a otro, siempre y cuando opere el concepto de simpatía. Después de todo, la simpatía es un principio vinculante, un desplazamiento, que nos permite como seres sociales identificarnos con el Otro y ponernos en su lugar, lo que en otras palabras quiere decir ver al Otro como un ser semejante a uno mismo y reconocerse en él y a través de él. Enseguida, la simpatía hace que rompamos la burbuja del egoísmo moral y estético; su presencia permite poder identificarse con lo le- jano y desconocido, al tiempo que posibilita fundir los intereses particulares con los intereses colectivos, bien sean morales o estéticos. A su imagen y semejanza, se crea una espacialidad en torno a lo imaginado capaz de propiciar vínculos afectivos entre las personas y de brindar las posibilidades para que dichos vínculos tengan experiencias directas e indirectas con cualquier persona u objeto del mundo.

De ahí se infiere que Hume y Shaftesbury valoren la imaginación como esa herramienta transformadora que facilita la convivencia civilizada y la construcción de la sociedad como tal; ella juega un papel protagónico para una socialización estructurada en la conversación. Al tiempo, la simpatía se transforma en ese espacio en el que la moral y la estética construyen una comunidad civilizada que aspira a desvirtuar las eternas confrontaciones que empañan los buenos modales y afectan la vida pacífica. En ello, es la imaginación la que juega el valioso papel de posibilitar el intercambio de sentimientos, ponernos en el lugar del Otro e identificarnos con lo más lejano y diferente, y todo esto sucede mientras que su gran poder civilizador se desborda y nos induce a hacer uso de nuestro 
ingenio y de nuestro buen humor (Solórzano, 2008, 36).

\section{Conclusiones}

Pertrechando en las ideas de Addison, se reconoce un primer paso para abordar perspectivas filosóficas que puedan traslaparse, aplicarse y enriquecer la geografía de las emociones. Lo mismo habría que decir respecto a pensadores como Hume (1741, ed. 1989; 1757, ed. 1990), Shaftesbury (1711, ed. 1964), Kant (1798, ed. 1935; 1790, ed.1991), Gilpin (1791, ed. 2004) o Price (1794, ed. 1810), quienes, sin duda, aportarían nuevos sentidos a la geografía que no han sido destacados suficientemente. Se intuye que la historia efectual sería una herramienta óptima para abordar el cruce de caminos entre un pasado y un presente, entre una teoría estética acuñada en el siglo XVIII y una nueva vertiente de la geografía preocupada por el valor que lo sensorial tiene para la construcción de la vida pública, los efectos de la imaginación y la construcción de entornos.

En un siglo en el que la geografía nace como ciencia moderna y la estética sienta serios debates sobre el protagonismo que la subjetivi- dad tiene para la vida común, la valoración sensible del paisaje y de prácticas como el caminar por un espacio se convierte en antecedentes de las vertientes geográficas contemporáneas, en las que la sensibilidad opera como conciencia espacial y en las que prevalece un marcado interés por la incidencia que los recuerdos tienen para la percepción.

Las prácticas que hacen uso del paisaje abren un espacio a la vida humana, un espacio en el cual esta se desarrolla y se realiza según determinadas formas de la subjetividad, pero también de la eticidad que implica la vida compartida. Las discretas expresiones de lo pintoresco, coloreadas por la sorpresa, lo interesante, lo agradable, el detalle y lo banal, reflejan la manera como una sociedad encuentra en actividades prosaicas la forma de contrarrestar el egoísmo, al tiempo que crea una imagen de sí misma impulsando el contenido fundamental de la época burguesa. A la luz de lo anterior habría que pensar, entonces, que en las ideas filosóficas de autores como Addison se encuentran antecedentes de cómo la subjetividad configura un espacio de encuentro y una conciencia valorativa de los hábitos 
donde operan perspectivas geográficas asociadas a la emocionalidad y los afectos.

Estas aportaciones demarcan visiblemente los espacios, territorios y lugares cotidianos que fueron resignificados gracias a la sensibilidad, posibilitando la emergencia de prácticas, ritos y actividades que giran en torno a lo agradable, el diálogo y el fortalecimiento de los vínculos sociales. En esto, la imaginación y la simpatía se consolidan como territorios de encuentro de ideas, juicios y opiniones que se apartan de los conceptos normativos y de la figura de una autoridad que determine las propiedades de la vida compartida. En este sentido, la naturaleza, sus objetos y, sobre todo, sus detalles modifican enteramente la subjetividad a través de revelaciones de insignificancias que entran en el repertorio de gustos para avivar la llama de la sorpresa y enriquecer el gozo y las sensaciones. En este punto, la comunicabilidad de esas sensaciones determina el valor de la emocionalidad, pues han de poderse comunicar a los demás, y es de allí que nace la interacción discursiva, cuya razón de ser es la sana discusión. Cuerpo y subjetividad se tejen en el magma de la simpatía, de la que se vale el sujeto para explorar unas territorialidades de la experiencia en un constante ir $y$ venir cada vez que se pone en el lugar del otro, derogando las fronteras del egoísmo.

Mantener constantes relaciones con el otro es entender lo pintoresco como ese espacio de diálogo cuyo telón de fondo es lo curioso y lo agradable, espacio en el que la experiencia ética y estética gana sentido. Desde esta perspectiva, es posible concebir el espacio del paisaje como un escenario, un teatro mundi, en el que, desde la facticidad, se elabora la experiencia humana. En tanto el cuerpo y las emociones son protagonistas de lo cotidiano, la experiencia de vivir en el mundo depende de una valoración sensible e intersubjetiva, de una simpatía que oriente las prácticas y actitudes, la confrontación de puntos de vista y enriquezca el contexto cultural dado. En esto, el gusto por lo agradable plantea valoraciones éticas y estéticas que nacen de la mera disposición al diálogo y de la afortunada e inconclusa expectativa de acuerdo.

Como puede concluirse, el ser en común transita en un vasto y quebrado territorio en el que no operan 
los principios universales, los modelos únicos de verdad $\mathrm{y}$, mucho menos, los juicios estrictamente políticos. Por el contrario, el ser en común es más una aspiración, una expectativa que se hace y se deshace y que conservaría equi- valencias con el gusto transitorio que la humanidad siente por las curiosidades del paisaje, un gusto que se renueva de acuerdo con los entendimientos mutuos y el reconocimiento de la pluralidad.

\section{Referencias}

Addison, J. (1991). Los placeres de la imaginación y otros ensayos. Madrid: Editorial Visor (1. Publicación, 1712).

Addison, J. (12 de abril de 20016). The Spectador. Justice, Candour, Equanimity, Zeal and Eloquence. (Mensaje en un Blog). N. ${ }^{\circ} 37$, Recuperado de http://elmismodiario.blogspot. com.co/2006/04/n-37.html.

Anderson, K. y Smith, S. (2001). (Eds.). Editorial: Emotional geographies. Transactions of the Institute of British Geographers, 26(1), 7-10.

Burke, E. (1987). Indagación filosófica sobre el origen de nuestras ideas acerca de lo sublime y lo bello. Madrid: Tecnos. (1. ${ }^{\text {a }}$ Publicación, 1757).

Careri, F. (2009). El andar como práctica estética. Barcelona: Gustavo Gili.

Certeau, M. (1996). La invención de lo cotidiano. 1 Artes de hacer. México: Universidad Iberoamericana. (1. a Publicación, 1980).

Davidson, J. y Milligan, C. (2004). Embodying Emotion Sensing Space: Introducing emotional geographies, Social \& Cultural Geography, 5(4), 523-532.

Dickie, G. (2003). El siglo del gusto. La odisea filosófica del gusto en el siglo XVIII. Madrid: Gráficas Rógar.

Gilpin, W. (2004). Tres ensayos sobre la belleza pintoresca. Madrid: Abada (1. a Publicación, 1791).

Kant, I. (1935). Antropología en el sentido pragmático. Madrid: Editorial Revista de Occidente (1. ${ }^{\text {a }}$ Publicación, 1798).

Kant, I. (1991). Crítica de la facultad de juzgar. Caracas: Monte Ávila (1. ${ }^{a}$ Publicación, 1790).

Kartz, J. (2001). How Emotions Work. Chicago: University of Chicago Press. 
Heidegger, M. (1999). Ontología. Hermenéutica de la facticidad. Madrid: Alianza (1. Publicación, 1999)

Hume, D. (1989). La norma del gusto y otros ensayos. Barcelona: Península (1. Publicación, 1741).

Hume, D. (1990). Disertación sobre las pasiones y otros ensayos morales. Barcelona: Anthropos (1. ${ }^{a}$ Publicación, 1757).

Hutcheson, F. (1992). Una investigación sobre el origen de nuestra belleza. Madrid: Tecnos (1. ${ }^{\mathrm{a}}$ Publicación, 1725).

Lévinas, E. (1987). Totalidad e infinito. Ensayo sobre la exterioridad. Salamanca: Sígueme (1. ${ }^{\mathrm{a}}$ Publicación, 1961).

Merleau-Ponty, M. (1996). Fenomenología de la percepción. Barcelona: Altaya (1. a Publicación, 1945).

Pochat, G. (2008). Historia de la estética y de la teoría del arte. Madrid: Akal.

Price, U. (1810). Essay on the Picturesque, as Compared with the Sublime and the Beautiful. Londres: Mawman (1. a Publicación, 1794).

Reymond, W. (1970). The English novel from Dickens to Lawrence. New York: Oxford University Press.

Ruiz, M. (2012). La hermenéutica de la facticidad dialógica en perspectiva moral. Observaciones para un diálogo con la sociedad y la cultura. En L. García Vélez, Pensar lo cotidiano: ensayos hermenéuticos de la sociedad y la cultura (pp. 169-234). Medellín: UPB.

Solórzano, A. (2008). El tiempo de lo neopintoresco: un recorrido por las sendas del gusto agradable. Medellín: UPB.

Shaftesbury, L. (1964). Characteristics. Indianapolis: Ed. de John M. Robertson (1. Publicación, 1711).

Vilard, G. (2000). El desorden estético. Ensayos. Barcelona: Idea Books.

Recepción: 8 de octubre de 2015

Evaluación: 11 de diciembre de 2015

Aprobación: 5 de febrero de 2016 